\title{
Clinical presentation of ruptured intracranial aneurysm
}

\author{
MARTIN SARNER AND F. CLIFFORD ROSE \\ From Atkinson Morley's (St. George's) Hospital, London
}

In a recent study, ruptured intracranial aneurysm was found in $28 \%$ of all cerebrovascular deaths under the age of 60 (Crawford and Sarner, 1965), and angiography reveals it as the cause of approximately $60 \%$ of all cases of subarachnoid haemorrhage (McKissock, Paine, and Walsh, 1958). Although the overall mortality from ruptured intracranial aneurysm remains in the region of $50 \%$, it has been shown that this can be lowered by surgical intervention, depending on the site of the aneurysm (McKissock, Richardson, and Walsh, $1960,1962,1965)$. If the presence and site of an aneurysm could be diagnosed by the clinical presentation, the management of subarachnoid haemorrhage might be made more definitive. We have therefore studied the gross presenting clinical features in a large number of cases of subarachnoid haemorrhage in which a single intracranial aneurysm was subsequently revealed by arteriography or necropsy.

\section{CASE MATERIAL}

The records of all cases of subarachnoid haemorrhage caused by proved ruptured intracranial aneurysm were analysed in respect of the recorded history and the physical signs present on the patients' admission to Atkinson Morley's Hospital, London, during the five-year period, 1958 to 1962. Cases of multiple aneurysms were excluded from this study and there were 962 cases in all.

\section{RESULTS}

Table I shows the clinical material analysed as to sex and site. The 'anterior' group includes aneurysms arising from the anterior cerebral-anterior communicating artery complex, the 'middle' group indicates those arising from the middle cerebral artery, and the 'posterior' group includes those arising from the posterior communicating-posterior cerebral artery complex. The vertebro-basilar group includes aneurysms arising from the vertebral and

'Present address: Dept. of Neurology, Charing Cross Hospital, London W.C.2

Requests for reprints should be addressed to F. Clifford Rose.
TABLE I

962 CASES OF PROVED RUPTURED INTRACRANIAL ANEURYSMS 1958-1962

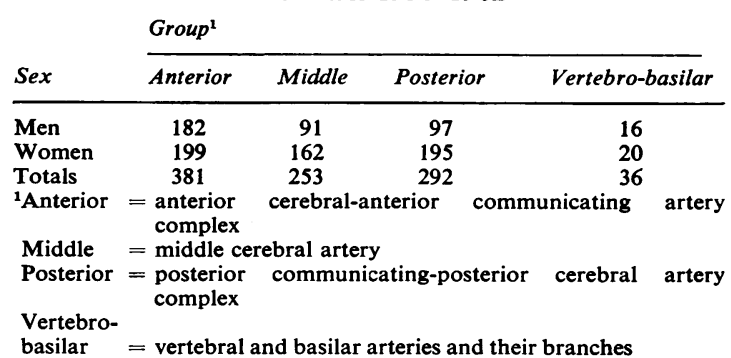

basilar arteries and their branches. The percentage of aneurysms occurring in the various sites is in accordance with previous reports (McDonald and Korb, 1939; Bull, 1962), the anterior group forming a slightly higher percentage than the middle or posterior groups and the vertebro-basilar group being by far the smallest. The sex incidence is equal in the anterior group but middle and posterior aneurysms are twice as common in females. This accords with the suggestion that males with ruptured cerebral aneurysms may not survive long enough to be transferred for neurosurgical investigation (Crawford and Sarner, 1965).

SYMPTOMS

HEADACHE Table II shows the relationship between

TABLE II

SITE OF HEADACHE

Site of Headache

Anterior Middle Posterior $\begin{aligned} & \text { Vertebro- All } \\ & \text { basilar }\end{aligned}$

Total number of

cases

Occipital (\%)

Frontal (\%)

Temporal (\%)

Not localized (\%)

None (\%)

67 
the site of aneurysm and the presence and localization of headache. The most striking finding is that only $21 \%$ of cases were recorded as having the classical occipital headache once considered typical of subarachnoid haemorrhage. In $15 \%$ the headache was frontal or retro-ocular and in $32 \%$ it was not localized at all. Twenty-three per cent. ( 232 cases) were not recorded as having had a headache but this was usually because the patients presented in coma (116 cases) or were too drowsy to give a history. In only 77 cases $(8 \%)$ was the headache on one side and, although this was an accurate symptom in lateralizing the aneurysm in two-thirds of these cases, it was of no value in discriminating between anterior, middle, or posterior aneurysms.

DISTURBANCE OF CONSCIOUSNESS From Table III it can be seen that half the patients had been in coma at some time and this was irrespective of the site of the aneurysm. Confusion, as evidenced by inability to give a coherent history, was recorded in a higher percentage of the middle group but this may reflect the difficulty in distinguishing this from dysphasia, a common finding when the aneurysm arises from the middle cerebral artery of the dominant side.

TABLE I II

DISTURBANCE OF CONSCIOUSNESS AND OTHER SYMPTOMS

\begin{tabular}{lrrrrr} 
& Anterior & Middle & Posterior & $\begin{array}{c}\text { Vertebro- } \\
\text { basilar }\end{array}$ & $\begin{array}{c}\text { All } \\
\text { Sites }\end{array}$ \\
\hline Total number & 381 & 253 & 292 & 36 & 962 \\
Coma (\%) & 52 & 53 & 51 & 49 & 52 \\
Confusion (\%) & 11 & 16 & 10 & 22 & 12 \\
Fits at onset (\%) & 10 & 9 & 4 & 14 & 8 \\
$\begin{array}{l}\text { Nausea or vomiting } \\
\text { (\%) }\end{array}$ & 55 & 38 & 39 & 40 & 45 \\
Paraesthesiae and & & & & & \\
numbness (\%) & 3 & 5 & 3 & nil & 4
\end{tabular}

FITS AT ONSET Fits at the onset of subarachnoid haemorrhage were more frequent in the anterior and middle groups and less so in the posterior group (Table III); this is to be expected as the frontoparietal areas are the most epileptogenic (Rose and Sarner, 1965).

NAUSEA OR VOMITING These were more frequent in the anterior than in the middle or posterior groups (Table III).

PARAESTHESIAE AND NUMBNESS These were rare symptoms but were slightly more frequent in the middle group, as would be expected in cases where there is likely to be ischaemia of the post-central areas. These symptoms were not recorded at all in the vertebro-basilar group but no firm conclusion can be drawn because of the relatively small number of cases.

OTHER SYMPTOMS Backache, photophobia, double vision, and shoulder pain were some of the other symptoms recorded but there was no association between any of these and the site of the aneurysm.

PRECIPITATING FACTORS Fifty cases were recorded as having occurred at the time of physical effort, e.g., cranking a car or running. A further 17 patients bled while straining at stool or sneezing, 20 while bending down, and six patients, one of whom was a woman, developed haemorrhage during sexual intercourse.

STATE OF CONSCIOUSNESS As noted previously, the state of consciousness, either at the onset of the bleeding on admission to hospital, was no guide to the site of the aneurysm (Table IV).

TABLE IV

STATE OF CONSCIOUSNESS AND PRESENCE OF MENINGISM ON ADMISSION

\begin{tabular}{lccccc} 
& Anterior & Middle & Posterior & $\begin{array}{c}\text { Vertebro- } \\
\text { basilar }\end{array}$ & $\begin{array}{c}\text { All } \\
\text { Sites }\end{array}$ \\
\hline Total number & 381 & 253 & 292 & 36 & 962 \\
$\begin{array}{l}\text { State of } \\
\text { Consciousness (\%) }\end{array}$ & & & & & \\
$\quad \begin{array}{l}\text { Alert } \\
\text { Drowsy }\end{array}$ & 50 & 50 & 54 & 50 & 50 \\
$\quad \begin{array}{l}\text { Comatose } \\
\text { Meningism (\%) }\end{array}$ & 13 & 37 & 37 & 30 & 36 \\
& 67 & 67 & 59 & 68 & 64
\end{tabular}

MENINGISM As evidence by neck stiffness, meningism was recorded as present in 622 cases at the time of admission to Atkinson Morley's Hospital (Table IV). Of these, 282 were drowsy and 53 were in coma. There was no reference to meningism in 340 cases; this may be explained partly on the basis of a disturbance of consciousness (drowsy 70 cases, coma 63 cases), but the majority of this group had completed a period of bed rest at another hospital before referral.

OPHTHALMOLOGICAL SIGNS These are set out in Table V.

TABLE V

OPHTHALMOLOGICAL SIGNS

Anterior Middle Posterior Vertebro- All

basilar Sites

Total number

Anisocoria (\%)

Third nerve palsy ( $\%$

Intraocular

haemorrhage $(\%)$

Papilloedema (\%) 
Unequal pupils were found in 112 cases (11\%) most of these being in the posterior group.

A third nerve palsy, either partial or complete, occurred in 66 cases, the vast majority being in the posterior group.

Intra-ocular haemorrhages, either vitreous, subhyaloid or preretinal, occurred in 121 cases and were seen less frequently in the posterior group.

Papilloedema occurred in 90 cases, being less common in the posterior group, possibly due to the lower incidence of intracerebral haematoma here.

CEREBRAL HEMISPHERE SIGNS Table VI summarizes the incidence of these signs.

TABLE VI

CEREBRAL HEMISPHERE SIGNS

Anterior Middle Posterior Vertebro- All basilar Sites

\begin{tabular}{lrrrrr}
\hline Total number & 381 & 253 & 292 & 36 & 962 \\
$\begin{array}{l}\text { Dysphasia (\%) } \\
\text { Homonymous }\end{array}$ & 12 & 20 & 9 & 3 & 13 \\
hemianopia (\%) & 5 & 16 & 10 & 3 & 9 \\
$\begin{array}{l}\text { Reflex changes (\%) } \\
\text { Motor defects (\%) }\end{array}$ & 21 & 19 & 18 & 32 & 19 \\
$\begin{array}{l}\text { Sensory } \\
\text { disturbances (\%) }\end{array}$ & nil & 11 & 5 & 3 & 5
\end{tabular}

Dysphasia and aphasia were noted in 124 cases and were twice as common in the middle as in the other groups.

Homonymous hemianopia was recorded in 91 cases; it was three times more common in the middle than in the anterior group, the posterior group being intermediate.

Reflex changes were as common in the anterior and posterior groups as in the middle group.

Motor defect, either monoplegia or hemiplegia, was, as expected, far more common in the middle group.

Sensory disturbances, including hemi-anaesthesia, hemi-hypaesthesia and tactile inattention, were uncommon. They were usually associated with motor defect and were again more common in the middle group.

No LOCALIZING SIGNS In $39 \%$ of all cases (378) there were no localizing signs, i.e., neither cranial nerve palsy, visual field defect, nor motor or sensory changes in the limbs (Table VII). Although less

TABLE VII

\begin{tabular}{llllll}
\multicolumn{7}{c}{ NO LOCALIZING SIGNS } & & \\
& Anterior & Middle & Posterior & $\begin{array}{l}\text { Vertebro- } \\
\text { basilar }\end{array}$ & $\begin{array}{l}\text { All } \\
\text { Sites }\end{array}$ \\
\hline Total number & 381 & 253 & 292 & 36 & 962 \\
& $(45 \%)$ & $(30 \%)$ & $(39 \%)$ & $(42 \%)$ & $(39 \%)$
\end{tabular}

surprising in the anterior group, where nearly one half of the cases had no localizing signs, this was also true of nearly one third of the middle group.

\section{DISCUSSION}

The increasing diagnosis of ruptured intracranial aneurysm due to the more frequent use of arteriography has not been accompanied by a more precise delineation of related clinical syndromes. Earlier clinical studies concerned either the less common unruptured aneurysm (Meadows, 1951) or subarachnoid haemorrhage in which the diagnosis was confirmed by arteriography in only a minority of cases (Walton, 1956). Only by a study of a large number of proven cases can the reliability of the classical textbook descriptions be assessed.

This retrospective survey suffers the usual limitations of case-note data and for this reason we have limited our study to gross clinical features only; it should also be borne in mind that the cases were a selected group in that they were suitable for investigation by reason of age and clinical state and, secondly, had survived long enough to be investigated. In spite of these limitations several interesting features are revealed.

Only $21 \%$ of cases presented with a history of classical occipital headache; more commonly the headache was generalized (one third of cases). In nearly a quarter there was no record of headache at all, but this may well have been due either to the presence of coma or to a retrograde amnesia. Lateralization of the headache occurred only rarely (less than $10 \%$ ) and did not always indicate the site of the bleed, a point noted by others (Henderson, 1955; Frankel and Alpers, 1955; Walker, 1956; Dimsdale and Logue, 1959). Site of the headache was most unreliable as a guide to localization of the aneurysm, a ruptured posterior aneurysm being as likely to have a frontal as an occipital headache. Coma occurred in half the cases irrespective of the site of the aneurysm; this is contrary to the usual belief that loss of consciousness is more common in aneurysms of the anterior cerebral or anterior communicating arteries, the branches of which supply the hypothalamus. Patients who had bled from an aneurysm in the posterior group were slightly more likely to regain consciousness by the time of admission.

A convulsive onset was also a poor guide to the site of the aneurysm as this occurred in all groups; fits were more common in the anterior and middle groups as would be expected from the greater incidence of intracerebral haematoma in these groups (Crompton, 1962), and the fact that the fronto-parietal regions are the most epileptogenic. 
Nausea and vomiting occurred in less than half the cases, other symptoms such as sweating, photophobia, or limb pain due to nerve root irritations being rarely recorded. Symptoms referable to the limbs were also rare but slightly more common in the middle group. The transient weakness of limbs that has been reported in association with vertebro-basilar aneurysm (Dimsdale and Logue, 1959) was not recorded in this series.

The association of a third nerve palsy and an aneurysm on the terminal part of the internal carotid artery or the posterior communicating artery is well known (Meadows, 1951; Walker, 1956), and was confirmed by this series; however, it may occur with ruptured aneurysms at other sites, although much less commonly. Only a minority $(17 \%)$ of cases of ruptured posterior aneurysms had evidence of an oculomotor palsy, but its presence was a helpful localizing sign. The earliest indication of compression of the third nerve is a dilated pupil, since the pupillo-constrictor (parasympathetic) fibres travel in this nerve peripherally on its supero-medial aspect and would be adjacent to a posteriorly situated aneurysm; a unilateral dilated pupil usually indicates the side of the bleed. Of the $11 \%$ of cases in which this was present (that is, a unilateral dilated pupil), the majority occurred in the posterior group, but the incidence of this physical sign was just as common in the vertebro-basilar group as in the posterior group; in the other groups the unilateral dilated pupil was presumably due to compression of the third nerve from tentorial herniation consequent upon intracerebral oedema or haematoma.

Papilloedema $(9 \%)$ and intraocular haemorrhage $(12 \%)$ occurred with aneurysms at all sites but each was slightly less frequent in the posterior group, possibly due to the lower incidence of intracerebral haematoma with this aneurysm (Crompton, (1962).

Visual field defects occurring in cases of subarachnoid haemorrhage may be difficult to assess because of lack of cooperation from the patient or the presence of intra-ocular haemorrhages. However, homonymous hemianopia was said to be present in $16 \%$ of the middle and $10 \%$ of the posterior group.

Signs relating to lesions of the cerebral hemispheres such as dysphasia, hemiparesis, or hemianaesthesia occurred more commonly in the middle group, as noted already (Frankel and Alpers, 1955; Walker, 1956); hyperreflexia alone appeared to be slightly more common in the anterior group.

Nearly $40 \%$ (378 cases) had no localizing neurological signs, and we feel that this is of great importance. Together with the other findings it indicates the uncertainty of clinical localization of a ruptured intracranial aneurysm. The site of an aneurysm determines its suitability for surgical treatment; the only certain way to establish this is by arteriography which should be carried out in every patient well enough to be investigated.

\section{SUMMARY}

Nine hundred and sixty-two cases of proved ruptured intracranial aneurysm have been analysed with regard to their gross presenting clinical features; the distribution of cases was comparable with other large series.

Only a minority of cases presented with the classical picture of occipital headache; meningeal irritation was not recorded in one third. Loss of consciousness occurred in approximately half the cases, irrespective of the site of aneurysm.

The most valuable localizing signs were unilateral mydriasis or oculomotor palsy indicating a posterior aneurysm and parietal lobe signs suggesting a middle group aneurysm; no single physical sign was pathognomonic of one aneurysm site.

The results of surgical treatment of ruptured intracranial aneurysm depend on its site; since this cannot be ascertained with certainty by clinical means, arteriography is mandatory.

We should like to thank Messrs. W. M. McKissock, L. S. Walsh, and A. E. Richardson for permission to study their patients. This work was carried out whilst one of us (M.S.) was in receipt of a grant from the National Institute of Health, Bethesda, U.S.A.

\section{REFERENCES}

Bull, J. W. D. (1962) Contribution of radiology to the study of intracranial aneurysms. Brit. med. J., 2, 1701-1708.

Crawford, M. D., and Sarner, M. (1965). Ruptured intracranial aneurysm. Community study. Lancet, 2, 1254-1257.

Crompton, M. R. (1962). Intracerebral haematoma complicating ruptured cerebral berry aneurysm. J. Neurol. Neurosurg. Psychiat., 25, 378-386.

Dimsdale, H., and Logue, V. (1959). Ruptured posterior fossa aneurysms and their surgical treatment. Ibid., 22, 202-217.

Frankel, K., and Alpers,, B. J. (1955). The clinical syndrome of aneurysm of the middle cerebral artery. Arch. Neurol. Psychiat. (Chic.), 74, 46-67.

Henderson, J. W. (1955). Intracranial artery aneurysms. Trans. Amer. ophthal. Soc., 53, 349-462.

McDonald, C. A., and Korb, M. (1939). Intracranial aneurysms. Arch. Neurol. Psychiat. (Chic.)., 42, 298-328.

McKissock, W.,Paine, K., and Walsh, L. (1958). Further observations on subarachnoid haemorrhage. J. Neurol. Neurosurg. Psychiat., 21, 239-248.

—, Richardson, A., and Walsh, L. (1960). Posterior-communicating aneurysms. Lancet, 1, 1203-1206.

,,--- (1962). Middle-cerebral aneurysms. Ibid., 2, 417-421. 1, (1965). Anterior communicating aneurysms. Ibid., 1, 873-876.

Meadows, S. P. (1951). Intracranial aneurysms. In Modern Trends in Neurology, edited by A. Feiling, pp. 391-465, Butterworth, London.

Rose, F. C., and Sarner, M. (1965). Epilepsy after ruptured intracranial aneurysm. Brit. med. J., 1, 18-21.

Walker, A. E. (1956). Clinical localization of intracranial aneurysms and vascular anomalies. Neurology (Minneap.), 6, 79-90.

Walton, J. N. (1956). Subarachnoid Haemorrhage, Livingstone, Edinburgh. 